\title{
Hemodynamic assessment of pneumopericardium by echocardiography
}

\section{Matias Trbušić*}

University Hospital Centre "Sestre milosrdnice", Zagreb, Croatia
KEYWORDS: pneumopericardium, cardiac tamponade, pericardiocentesis. CITATION: Cardiol Croat. 2017;12(4):124. I https://doi.org/10.15836/ccar2017.124

*ADDRESS FOR CORRESPONDENCE: Matias Trbušić, Klinički bolnički centar Sestre milosrdnice, Vinogradska 29, HR-10000 Zagreb, Croatia. / Phone: +385-91-506-2986 / E-mail: matias.trbusic@gmail.com ORCID: Matias Trbušić, http://orcid.org/0000-0001-9428-454X

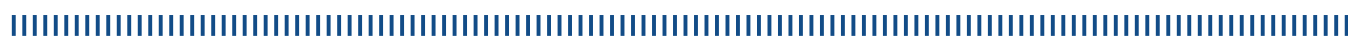

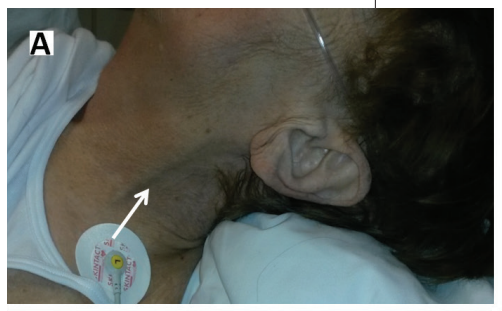

B

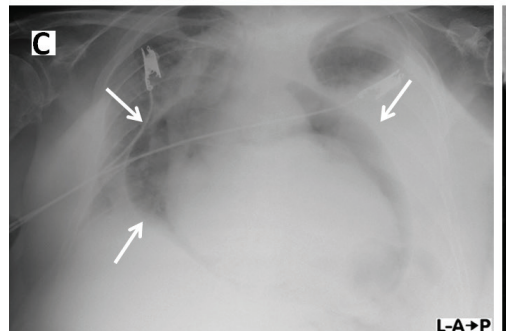

D

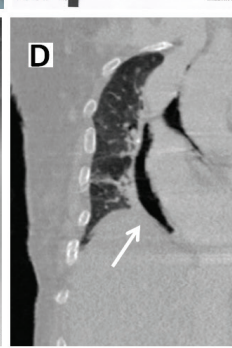

(a)

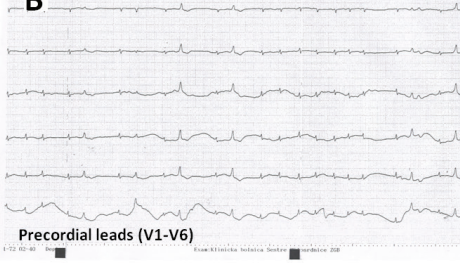

D
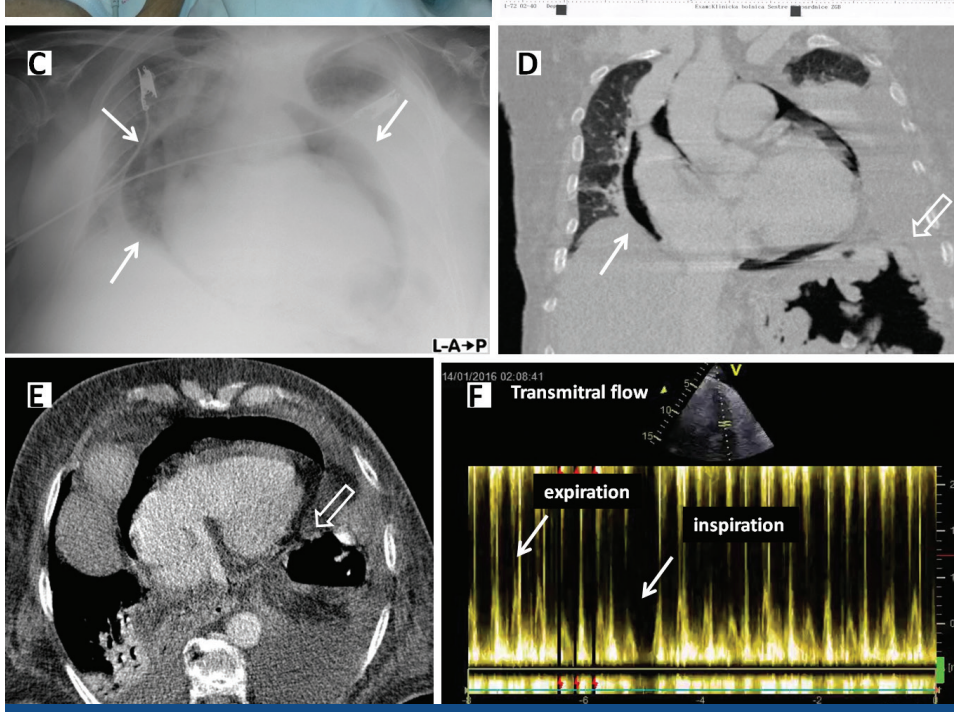

FIGURE 1. A) dilated neck veins, B) Electrocardiogram: frontal end precordial micro-voltage, C) $X$ ray: halo sign around the heart, D) CT scan: halo sign around the heart (full arrow), infiltrating colon carcinoma (empty arrow), E) CT scan: possible place of communication between the colon and the pericardium, F) Echocardiography - Pulsed Doppler of transmitral flow: $>25 \%$ respiratory variations.
Background: Pneumopericardium is a rare condition defined as a collection of air in the pericardial cavity. It is usually result of chest injuries, iatrogenic causes (bone marrow puncture, thoracic surgery, pericardiocentesis, endoscopic procedures), and infective agents causing purulent gas - producing pericarditis., ${ }^{1,2}$

Case report: We represent a case of 82-year old female patient with spontaneous pneumopericardium caused by malignant ulcer that created fistula between the pericardium and colon. She was admitted in very severe condition with chest pain, severe respiratory distress, hypotension, distended neck veins and tachyarrhythmia. High blood leukocyte, high $\mathrm{C}$ reactive protein levels and combined respiratory and metabolic acidosis were present. Electrocardiogram showed atrial fibrillation and diffuse micro voltage. Chest X ray and CT showed normal sized heart surrounded by air (halo sign) below the aortic arch, and large left pleural effusion. CT also revealed neoplastic process of the transverse colon infiltrating stomach and diaphragm. Due to intrapericardial spontaneous contrast echoes the image quality of 2-D echocardiography was poor making difficult to verify signs typical for tamponade such as early diastolic right ventricular collapse and early diastolic right atrial collapse (Figure 1). Nevertheless, significant respiratory variations ( $>25 \%)$ in transmitral and transtricuspid blood flow velocities have been noticed by Pulsed Doppler echocardiography. Also, despite the air within the pericardium, inferior vena cava was well visualized showing dilatation and lack of significant inspiratory collapse. It was concluded that the patient has tension pneumopericardium and resulting cardiac tamponade caused probably by a valve mechanism. ${ }^{3} \mathrm{Un}-$ der fluoroscopy control emergent pericardiocentesis was performed with needle extraction of $160 \mathrm{~mL}$ of very unpleasantly smelling air. Mechanical ventilation was also started together with antibiotic therapy, volume replacement and pleural drainage. The patient was stabilized and next day transferred to another clinic in overall stable condition were the complex abdominal surgery was performed. In conclusion, spontaneous pneumopericardium is a rare life threatening condition that can be caused by infiltrating malignant process. It can be rapidly recognized by physical examination, X ray, CT and fluoroscopy. Despite the low 2D image quality due to air bubbles, echocardiography, especially Pulsed Doppler and inferior vena cava visualization, an undeniable role in hemodynamic assessment and verification of tamponade.

LITERATURE IIIIIIIIIIIIIIIIIIIIIIIIIIIIIIIIIIIIIIIIIIIIIIIIIIIIIIIIIIIIIIIIIIIIIIIIIIIIIIIIIIIIIIIIIIIIIIIIIIIIIII Westermann GW, Suwelack B. Spontaneous pneumopericardium due to exertion. South Med J. 2003 Jan;96(1):50-2. https://doi.org/10.1097/01.SMJ.0000047762.92538.EC

2. Katzir D, Klinovsky E, Kent V, Shucri A, Gilboa Y. Spontaneous pneumopericardium: case report and review of the literature. Cardiology. 1989;76(4):305-8. https://doi.org/10.1159/000174508

3. Cummings RG, Wesly RL, Adams DH, Lowe JE. Pneumopericardium resulting in cardiac tamponade. Ann Thorac Surg. 1984 Jun;37(6):511-8 https://doi.org/10.1016/S0003-4975(10)61146-0 